crystals containing molecules of water"; M. Soutif and $Y$. Ayant (Grenoble), "Study of the water molecule in lithium sulphate monohydrate"; N. J. Poulis and G. E. G. Hardeman (Leyden), "Position of protons in $\mathrm{CuCl}_{2} \cdot 2 \mathrm{H}_{2} \mathrm{O}$ determined by the method of nuclear magnetic resonance"; W. Gordy (U.S.A.), "The spectra of water vapour in the millimetric range". W. A. Wooster

\section{INTERNATIONAL ELECTRO-ACOUSTICS CONGRESS}

A $\mathrm{N}$ "International Electro-acoustics Congress" was A held in Holland during June 16-24. The congress, which was organized by a Dutch Committee, presided over by Prof. C. W. Kosten, was the first venture sponsored by the newly formed International Committee of Acoustics (I.C.A.), an offshoot of Unesco. It was held in the main at the Technische Hoogeschool, Delft, and was attended by more than three hundred people, representing many countries.

After addresses by the president of the Congress, H. E. the Minister of Education and Prof. R. H. Bolt, president of the International Committee of Acoustics, the Congress settled down to hear general reviews of progress in the seven sections into which the subject had been divided. These are summarized below.

Section I: Sound Recording. R. Vermeulen described improvements which have been made in disk and tape recording. He pointed out the need for defining standards in reproduction apparatus. Frequency response is not the only criterion; the psychological attitude of the hearer and the auditorium in which he listens play a large part in appreciation. Advances in stereophony were pointed out and-later in the Philips works-a two-channel demonstration was given to show that the illusion of space in such a system is still imperfect.

Section II. Public Address Systems. Erwin Meyer pointed out that the Ioud-speaker remains the weakest link in this type of transduction, which has become so important in modern life. Usually it is more important, at least in speech, to get the high frequency amplified than the bass. Different types of microphones and arrays of loud-speakers were described, and the advantages of delay pick-ups as used in St. Paul's, London, for large auditoria was explained.

Section III : Measurements. L. Beranek emphasized the need for measuring devices which include the listener as part of the system. This science of psycho-acoustics is still in its infancy; but many acoustic measurements are valueless without it. On the purely physical side, the most important developments are in high-frequency microphones for use in a wide range of conditions, in the measurement of acoustic and mechanical impedance.

Section IV: Audiometers. P. Chavasse also pointed out the need for listener research in this field, which should cover not only psychological reaction but also measurements of a more physical character like the impedance of the external ear, diffraction of sound by the head, artificial ears, and establishment of a norm of hearing for all countries.

Section V: Ultrasonics. G. Bradfield described recent advances in transducer design for this range, now going up to $3,000 \mathrm{Mc}$./s., particularly those involving barium titanate and the ferrites. Trans- ducers for pulse excitation using Rochelle salt or long nickel tubes with the distant end immersed in grease have also been used in delay lines, while for ultrasonic cutting tools, 'Permendur' is used. The characteristics of many of these were discussed through their equivalent circuits or Argand diagrams. More study is needed of the launching of waves in solids, where the energy tends to be transferred to and from transverse and longitudinal waves, complicating the process.

Section VI : Musical Acoustics. E. G. Richardson described the benefits which this branch has derived from advances in electrical tone synthesis. Recent research has shown the importance of a knowledge of the formants (varying timbre over the scale) and transients of musical instruments in differentiating them and assessing their relative excellence. Work on the violin and the organ-pipe in particular was described.

Section VII : Lightweight Structures. C. W. Kosten pointed out the difficulties in building an insulating wall between two rooms without excessive weight. Flexural stiffness and resistance must be introduced to compensate for the light weight, and resonances must be distributed over the gamut. Both cavity walls and filled double-wall structures are employed.

After this the Congress divided into Sections, in each of which ten to a dozen papers were read, that of Section VI being enlivened by demonstrations on various musical instruments varying from bagpipes to just-tempered organs.

On two days visits to Hilversum Radio and Philips. Industries, Eindhoven, were made.

\section{EUROPEAN ASSOCIATION OF EXPLORATION GEOPHYSICISTS}

\section{PARIS MEETING}

$T$ HE fourth meeting (second annual meeting) of the European Association of Exploration Geophysicists was held in Paris during May 20-22, when about a hundred and fifty members were present, the president, A. van Weelden, being in the chair. Membership now stands at more than five hundred and fifty, a remarkable achievement since the Association's inauguration in December 1951. Affiliation with the Society of Exploration Geophysicists (U.S.A.) has recently been approved, and a paper entitled "The Significance of Diffraction in the Investigation of Faults"1 by T. Krey, presented ot the Association's meeting in London in May 1952 and published in the Journal of the Society of Exploration Geophysicists (before the Association's own journal, Geophysical Prospecting, was in being), has received the Society's award for the best paper during 1952:

In his presidential address, A. van Weelden discussed the various ways in which the results of gravity surveys are analysed, and emphasized the imperfections and ambiguities in the interpretations which are brought about by unjustified assumptions. In this regard, he stressed the necessity for close co-operation between geologist and geophysicist, a necessity which is sometimes not given full support.

Of the twenty-two papers presented at the meeting, seven were on seismic, six on electrical, four on magnetic, two on gravity and three on general problems in exploration geophysics. 
The interpretation of reflexion records obtained over fault zones is receiving much attention by workers in oil-field exploration, as oil may be found in stratigraphic traps up against the fault face, and in a paper by K. H. Seelis (Germany) the diagnostic features such as character of reflexion, abnormal dips, displacement of the reflected arrival and a variation of the velocity/depth distribution in crossing a fault were exemplified by records and dopth sections. The last feature was also discussed in a paper by $\mathrm{H}$. A. Rühmkorf (Germany), who noted that the travel times from a well geophone to two surface geophones equidistant, but in opposite directions, from the well differed by a small amount $(0.01-0.02$ sec.). It was pointed out in the subsequent discussion, however, that care must be taken to eliminate any time differences due to an uneven thickness of the very low velocity $(2,000 \mathrm{ft}$. $/$ sec. $)$ near-surface beds.

In computing depths to the reflecting bed, the normal procedure is to employ an average velocity; but this only holds for small dips. When the geological layers are much inclined, some allowance must be made for varying layer velocities, and $H$. Dürbaum (Germany) presented formulæ for the direct determination of them from the records; he also discussed the errors introduced by assuming average velocities in such cases. An interesting account of reflexion investigations in the Swabian Molasse basin in front of the Bavarian Alps was given by W. Elberkirch (Germany). Here the erratic glacial drift is largely responsible for the paucity of the reflexions; but the top of the Mesozoics appears to offer a useful key horizon, the deepest part of the Tertiary basin holding an estimated 10,000 ft. of sediments.

H. Menzel (Germany) described laboratory studies of the propagation of elastic waves in a solid with elastic afterworking. He found that high-frequency waves are not absorbed as is the case in visco-elastic theory, and considered that some modification of the latter theory in accounting for the shapes of seismic onsets is desirable.

All seismic workers are familiar with graphical methods of constructing depth-sections, but the conversion of a time-section when the velocity is not constant leads to refraction complications across the various seismic layers. To obviate lengthy computations, however, J. Dienesch and H. Richard (France) have evolved and presented geometric constructions in reflexion problems of this kind.

A most informative paper on explosives in seismic prospecting by S. H. Davidson, R. Westwater and J. Hancock (Great Britain) brought the seismic session to a close. Chemical stability, freedom from grit contamination and transportation and preparation of the explosive for lowering into the shot-hole were all discussed. In order to lessen the hazards in operation, a new explosive, 'Seismex', with an ammonium nitrate base, has been produced in recent years by Imperial Chemical Industries, Ltd., but owing to its hygroscopic nature it is cased in watertight tins ; it suffers the disadvantage, however, of not being able to stand up to the great pressures sustained by the nitroglycerine explosive, 'Geophex', which is capable of exploding under a water pressure of $1,000 \mathrm{lb}$. per sq. in. In the following discussion, some interesting observations were made on sympathetic explosions of a second buried charge situated a short distance from, and on firing, the first; methods for distinguishing between the sweating of nitroglycerine and the presence of water particles on the explosive surface in tropical climates were also described.

Geophysics is playing an increasing part in the coal mining industry, and the National Coal Board of Great Britain has a wide programme of research on problems affecting the safety of the mine and mine-worker from subsidence of unconsolidated strata and a waterlogged overburden. In a paper by G. M. Habberjam and J. T. Whetton, an account was given of a resistivity investigation into an old river valley in Coal Measure strata, the trend of the valley being completely delineated. A second paper by E. Jan Polak described the attempt to demarcate the freshwater Trias formations from the brackish Coal Measures; but lack of homogeneity in electrical properties of the rocks resulted in a rather indefinite boundary. The exploration for water by $(a)$ electrical and $(b)$ seismic refraction methods in the desert areas of Mauritania (Morocco) was discussed in an interesting paper by J. J. Breusse and G. Huot (France). Close agreement between the thicknesses of the claysandstone complex resting on a crystalline basement was found by the two methods, while it was also found possible to distinguish between fresh and saline water areas. Six drill holes put down afterwards corroborated the general results of the surveys.

The important branch of electrical surveying which has to do with measurements in bore holes was represented by three papers. The first, by A. P. Poirault (France), reviewed the development of gamma-ray logging, micro-logging and side-wall sampling as applied to holes drilled for minerals other than oil, and described the results obtained in the case of coal seams in England, lignite deposits in the Cologne basin and the potash beds in Alsace. A second paper, by I. Wendt (Germany), discussed a method using two counting tubes for determining the radioactive potassium in thin deposits, while a third paper, by L. Solaini (Italy), gave an account of an instrument for measuring resistivity with alternating current at $20 \mathrm{c} . / \mathrm{s}$.

In the magnetic section a paper by $\mathbf{S}$. Matweber and $\mathbf{K}$. Jung (Germany) described how a reasonable interpretation of a very detailed vertical intensity survey (station interval $30 \mathrm{ft}$.) in the Red Iron district of Lahn and Dill attributed some small-size anomalies of large magnitude to a variable magnetic content of underlying diabase. On drilling, however, iron ores rich in magnetite were penetrated at shallow depth before basement was reached. In discussion, it was agreed that measurements of the vertical gradient of intensity by means of observations on elevated platforms would lead to a nearer estimate of the depth to the magnetic disturbance. F. Sumi (Yugoslavia) introduced a somewhat academic note when he discussed the magnetic anomalies to be expected from spheres and cylinders, and A. Lundbak (Denmark) reviewed the limiting factors in airborne magnetic surveys and referred to some recent modifications of the fluxgate magnetometer. Most workers with the vertical magnetometer of the Schmidt type believe that constructional errors are eliminated by taking the mean of magnet readings in azimuths 180 degrees apart; but J. McG. Bruckshaw (Great Britain) demonstrated that, as the inclination of the knife edge is fixed by an arbitrary setting of the levels, elimination of errors due to this inclination and to misorientation is incomplete. Formulæ permitting the determination of the tolerance in knifeedge tilt and azimuth in any particular case were given. 
C. Aynard (France) presented a paper on the interpretation of the gravity results obtained in the Gharb basin of Morocco and compared them with the known geology and the results of seismic and electrical surveys ; it appeared that most of the local gravity features are related to the pre-Riff tectonics. In precision gravity surveys, corrections are made for diurnal variation, and C. Morelli (Italy) explained. that the determination of the diurnal variations for northern Italy now being effected at the Geophysical Observatory, Trieste, can be extended with slight modifications to almost the whole of Europe, the work being facilitated by the use of nomograms. In the following discussion it was agreed that the Council should consider the appointment of a committee to study this important matter.

Papers which compare the results of various surveys in the same area are particularly stimulating, and such was the case when A. M. Selem and C. Monnet (Italy) gave an account of the seismic reflexion, telluric and gravity surveys in the Ferrara area of northern Italy, where an early torsion-balance survey had indicated a broad uplift in the Tertiary and Mesozoic formations. A broad agreement was shown to exist among the results given by the three methods. A further comparison was made by means of the derived vertical gravity-gradient (using Baranov's formula presented at the previous meeting of the Association in Hanover) in the area where reflexions were poor; agreement with the telluric results was marked. Geological data from two wells drilled to $1,300 \mathrm{ft}$. and nearly $2,100 \mathrm{ft}$. over the uplift tended to support the geophysical conclusions.

The degree of certainty of the interpretation of geophysical results was discussed in a paper by $\mathbf{M}$. Matschinski (France). Here the problem was divided into four parts : (a) mathematical description of a hypothetical geological structure satisfying the geophysical data; (b) determination of the parameters defining the structure; $(c)$ the likelihood that these parameters are the only ones; and $(d)$ determination of the likelihood of the hypothesis itself. The necessity for accepting some limitation for parameter variation was discussed, and applications of the general theory to seismic and gravity measurements were given.

The technical session closed with a paper dealing with safety regulations in geophysical prospecting by H. Richard (France) and the showing of a "Technicolor' film entitled "Make no Mistake" (presented by courtesy of Geophysical Service Incorporated, U.S.A.). These provoked considerable discussion, and it was agreed that a special committee be formed to consider and make recommendations on this very important subject.

It is to be regretted that spoken language difficulties were emphasized by the almost complete lack of copies of the various papers. Abstracts were not available to members until just before the meeting, so that even if the speaker's language was understood, there was little or no time for a member to consider carefully the points brought out in a paper with the view of joining in the discussion. It is to be hoped that copies of the papers for the next meeting, probably in Italy, will be circulated well in advance, so that it would only be necessary for the speaker to dwell on the salient or controversial parts of his subject in a relatively short time, thus leaving a much desired longer time for the discussion.

Some very informative exchanges of experiences and ideas were made between members outside the lecture theatre, and this more personal contact is obviously a most attractive feature of the meetings. The Compagnie Générale de Géophysique and the Société de Prospection Electrique kindly made all the arrangements for the meeting, which included several enjoyable sight-seeing tours for members' wives.

The following officers were elected for 1953-54: President, D. T. Germain-Jones (Great Britain); Past President, A. van Weelden (Holland); VicePresident, J. Goguel (France) ; Secretary/Treasurer, B. Baars (Holland); Members of Council, A. Schleusener and F. Werner (Germany), J. L. Mathieu (France), T. Rocco (Italy), J. McG. Bruckshaw (Great Britain) and D. Malinqvist (Sweden).

T. C. Rrchards

${ }^{1}$ Geophysics, 17, No. 4 (Oct. 1952).

\section{LIBRARY FACILITIES IN THE UNITED STATES}

MONG the papers presented to the Library Association at its annual conference at Llandudno during April 28-May 1, that of Mr. R. W. L. Collison on aspects of co-operation in university and special libraries in the United States of America appears to be the one of most interest to scientific workers or technologists as such. Mr. Collison began by referring to the awareness of librarians in post-war America of the need for the closest co-operation between all types of libraries, particularly between those libraries which are in any way concerned with the advancement of research and scholarship, and to the extent to which practical co-operation between university and special libraries has already developed in the United States. Even many American librarians, however, are unaware of the full implications or of the general pattern. Much has been achieved, for example, by the wide exchange of catalogue entries betwcen university and specißl libraries interested in the same subject or group of subjects. From this it is but a short step to the co-operative planning of book purchase, such as the long-standing agreement between the John Crerar Library, the Chicago Public Library and the Newberry Library as to which subject-fields each will cover. Book- and serialwithdrawal has become a fruitful field for extensive co-operation, and the establishment of the Mid-West Inter-Library Centre in which, besides university libraries, the Illinois Institute of Technology and the John Crerar Library are co-operating, has led to substantial economies as well as to the filling of important lacunæ.

There is no inter-loan system as comprehensive as that established in Great Britain, continued $\mathrm{Mr}$. Collison; but some bibliographical centres have developed their services further than any single regional bureau in Britain. Almost evory field of research in the area has availed itself of the services of the Philadelphia Centre, and important industrial libraries are co-operating. The scale of assistance of university libraries to special libraries in the United States is unequalled in any other country, and the universities in the United States usually pay much attention to local industries and professions. Organizations on both sides are very willing to exchange publications, while the universities often undertake important schemes of research on behalf of Federal, 